\title{
Changes in smoking patterns after HIV diagnosis or antiretroviral treatment initiation: a global systematic review and meta-analysis
}

Jobert Richie Nansseu ${ }^{1,2}$, Dalhia Noelle Tounouga', Jean Jacques Noubiap ${ }^{3}$ and Jean Joel Bigna ${ }^{4,5^{*}}$

\begin{abstract}
Background: Tobacco consumption is more life-threatening in people living with human immunodeficiency virus (HIV) than within the general population; therefore, people living with HIV (PLWH) should be highly motivated to take action towards quitting smoking at or after HIV diagnosis. The aim of this systematic review with meta-analysis was to investigate changes in smoking habits among PLWH over time.
\end{abstract}

Main text: We considered prospective and retrospective cohort studies including PLWH aged 15 years and above, which have measured the prevalence of tobacco smoking (current, former or never) at study initiation and completion, and published between January 1, 2000 and April 15, 2018 without language or geographical restriction. We searched PubMed, EMBASE, Web of Science, Africa Journal Online, and Global Index Medicus. We used a random-effects model to pool data. Nine studies were included. The proportion of current and former smokers decreased slightly over time, around 2.5 and 3.8\%, respectively. However, the proportion of never smokers decreased sharply by 22.5\%, and there were 2.1 and 1.5\% PLWH who shifted from never and former smoking to current smoking, respectively. On the other hand, 10.5\% PLWH shifted from current to former smoking, 7.1\% tried to quit tobacco consumption but failed, and $10.1 \%$ stayed in the "never smoking" category over time.

Conclusions: PLWH seem not to change positively their smoking habits towards quitting tobacco consumption. There is urgent need to increase actions aimed at helping this vulnerable population to quit tobacco consumption, including individually tailored therapeutic education, psychosocial and pharmacologic supports.

Keywords: Smoking, HIV, AIDS, Tobacco, Global health

\section{Background}

Tobacco constitutes one of the leading causes of preventable deaths worldwide, killing over 7 million people each year among whom more than $80 \%$ occur in developing countries [1]. In addition, tobacco consumption accounts

\footnotetext{
* Correspondence: bignarimij@yahoo.fr

${ }^{4}$ Department of Epidemiology and Public Health, Centre Pasteur of Cameroon, PO Box 1274, Yaoundé, Cameroon

${ }^{5}$ School of Public Health, Faculty of Medicine, University of Paris Sud XI, Le Kremlin Bicêtre, France

Full list of author information is available at the end of the article
}

for almost 182 million disability-adjusted life year [1, 2]. Tobacco consumption increases the risk of developing chronic diseases such as cancers, cardiovascular diseases, chronic infections and chronic pulmonary diseases, particularly in people living with human immunodeficiency virus (HIV) [3-5]. In these populations specifically, more than $70 \%$ of whom are living in Africa [6], smoking is associated with a more rapid progression of the HIV disease with an increased likelihood of HIV-related complications, decreased adherence to antiretroviral therapy (ART), and

C C The Author(s). 2020 Open Access This article is licensed under a Creative Commons Attribution 4.0 International License, which permits use, sharing, adaptation, distribution and reproduction in any medium or format, as long as you give appropriate credit to the original author(s) and the source, provide a link to the Creative Commons licence, and indicate if changes were made. The images or other third party material in this article are included in the article's Creative Commons licence, unless indicated otherwise in a credit line to the material. If material is not included in the article's Creative Commons licence and your intended use is not permitted by statutory regulation or exceeds the permitted use, you will need to obtain permission directly from the copyright holder. To view a copy of this licence, visit http://creativecommons.org/licenses/by/4.0/ The Creative Commons Public Domain Dedication waiver (http://creativecommons.org/publicdomain/zero/1.0/) applies to the data made available in this article, unless otherwise stated in a credit line to the data. 
lowered virological and immunological responses to ART [3, 4, 7-11].

Studies have reported that smoking tobacco is a highly prevalent behaviour among people living with HIV (PLWH), with an average of 16-28 cigarettes smoked per day among those who smoke, which is an indicator of high nicotine dependence [10, 12-16]. Furthermore, the prevalence of smoking among PLWH is at least 1.3 folds higher (range 40-74\%) than in the general population (range 19-31\%) [10, 11, 13, 17, 18]. Therefore, smoking cessation should be considered as a priority by HIV care providers.

Strikingly, reasons for this higher prevalence of smoking among PLWH have not been well elucidated. Some evidence indicates that tobacco use among PLWH may be associated with some factors including substance use disorders (heroin, cocaine, marijuana, crack, heavy alcohol drinking), socioeconomic factors (unemployment, lower educational level, lower income), mental disorders or lack of access to health services, housing, and transportation [7, 10, 12, 15, 19, 20]. As far as the Health Promotion Model in HIV care is concerned, knowing one's HIV status is projected to increase self-motivation towards the control of one's health and then, motivate self-appraisal of health risks [21]. Accordingly, when a PLWH starts accepting his/her condition as serious and life-threatening, he/she may be motivated to take action in order to control the disease process by quitting unhealthy habits including smoking. Therefore, it is expected that positive smoking behaviour changes would occur in the course of HIVinfection. We designed and conducted a systematic review and meta-analysis to summarize evidence on the changes in smoking patterns after HIV diagnosis or ART initiation.

\section{Main text \\ Methods \\ Design}

This systematic review with meta-analysis was reported following the Meta-analysis Of Observational Studies in Epidemiology (MOOSE) guidelines (Table S1). This review was registered in the PROSPERO International Prospective Register of systematic reviews, registration number CRD42019123969. The Centre for Reviews and Dissemination guidelines were used as a reference for the methodology of this review [22].

\section{Criteria for considering studies for the review}

We considered prospective and retrospective cohort studies, before-and-after studies and control arm of randomized controlled trials which have assessed changes in smoking behaviours among PLWH. Studies had to include global adult ( $>15$ years) populations living with HIV infection who have experienced any change in their smoking habits at the time of HIV diagnosis or ART initiation. These changes might have been from current smoker (people who actually smoke) to former smoker (people who smoked and who stopped), from former smoker to current smoker, from former smoker to current smoker, or from never-smoker (people who have never smoked) to current smoker. Studies included in this review had to measure the prevalence (or enough data to compute this estimate) of tobacco smoking pattern (current, former, and never) at least two times (at initiation and completion). Studies lacking primary data or explicit method description were excluded, if after contacting authors at least twice the information was not provided. We also excluded studies wherein HIVnegative individuals had been included without the possibility to extract data only for HIV-infected people. Similarly, we did not consider cross-sectional or casecontrol studies, letters, reviews, commentaries, editorials, case reports, or case series.

\section{Search strategy used to identify relevant studies}

A comprehensive search of databases was performed by a review author to identify all relevant articles published from January 1, 2000 to April 19, 2018 regardless of either the language of publication or the geographical location. The following databases were screened: MEDLINE through PubMed, Excerpta Medica Database, Web of Science, Africa Journal Online, and Global Index Medicus. A predefined strategy using combination of relevant terms and their variants was used. Both text words and medical subject heading terms were used, including "HIV", "AIDS", "smoking", "tobacco" and "cigarette". The literature search strategy was adapted to suit each database. The search strategy conducted in PubMed is shown in Table S2. To identify other sources, reference lists of eligible articles and relevant reviews were manually scanned.

\section{Selection of included studies}

We developed and piloted a screening guide to make sure that all inclusion criteria were adhered to and consistently applied by all review authors. Two authors independently reviewed all identified citations on the basis of their titles and abstracts; then, the same authors independently assessed the full-texts of records deemed relevant or potentially relevant for eligibility. Any discrepancy between these authors was resolved through discussion and consensus, or arbitration by a third review author. The Cohen's kappa coefficient was used to assess the interrater agreements between authors for study selection and inclusion [23].

\section{Appraisal of the methodological quality of included studies}

The methodological quality of included studies was assessed using the Newcastle-Ottawa Scale version for cohort studies [24]. Considering that there is no validation 
study that provides a cut-off score for rating low-quality studies, we arbitrarily established that a study rated $0-3$, 4-6, or 7-9 points would be considered at high, moderate, or low risk of bias, respectively. Two authors independently assessed the study quality, with disagreements resolved by consensus.

\section{Data extraction and management}

We used a preconceived and standardized extraction form to collect our data from each study, conducted independently by two authors. Disagreements between these authors were reconciled through discussion and consensus, or arbitration by another author. The Cohen's kappa coefficient was used to assess the inter-rater agreements between authors for data extraction [23]. Data were abstracted from each study for the following elements: first author, year of publication, study objective(s) and design, period of data collection, country of study, setting, number of sites, sampling method, definitions used for current/former/ex/never-smoking, method of smoking assessment, period of smoking patterns measurement, mean/median duration of HIV, type of HIV, proportion on ART, mean/median duration of ART, mean/median age, age range, proportion of males, mean/median CD4 counts at study initiation/completion, mean/median viral load at study initiation/completion, mean/median duration of follow-up, total sample size/person-time of follow-up, number of PLWH with changes in smoking patterns, and study conclusion(s).

\section{Data synthesis including assessment of heterogeneity}

Meta-analysis was performed using 'meta' packages in $\mathrm{R}$ version 3.6.1 ( $R$ Core Team, $R$ foundation for Statistical Computing, Vienna, Austria). We pooled the studyspecific estimates using a random-effects meta-analysis model to obtain an overall summary estimate of the prevalence and mean across studies, after FreemanTukey double arc-sine transformation [25]. Estimates were reported with their 95\% confidence interval (95\% $C I$ ) and $95 \%$ prediction interval. Heterogeneity was assessed using the $X^{2}$ test on Cochrane's Q statistic [26], and quantified by calculating the $I^{2}$ [27]. Values of 25, 50 and $75 \%$ for $I^{2}$ represented low, medium and high heterogeneity, respectively. We assessed the presence of publication bias using the formal Egger's test [28]. A $P$-value $<0.10$ was considered indicative of statistically significant publication bias.

\section{Results}

\section{Study selection}

Initially, a total of 7135 records were identified. After exclusion of duplicates and screening titles and abstracts, 7114 records were found irrelevant and then excluded. The inter-rater agreements between review authors for study inclusion and data abstraction remained high: $\mathrm{K}=0.94$ and $\mathrm{K}=0.97$, respectively; $P<0.001$. Full-texts of the remaining 21 records were scrutinized for eligibility, among which 12 were excluded. In the end, nine studies were retained for the meta-analysis [19, 29-36] (Figure S1).

\section{Methodological quality and characteristics of included studies}

Four studies had a low risk of bias, five studies had a moderate risk of bias, and no study had a high risk of bias. In total, 25502 participants were included. All studies were prospective. Participants' inclusion and follow-up ranged between 1984 and 2014. Studies were conducted in USA $(n=5)$, Canada $(n=2)$, Uganda $(n=1)$, and Switzerland $(n=1)$. Seven studies were multisite and two were single site. Six studies were hospital-based, two were population-based, and one did not specify the site. History of smoking was assessed by self-reporting in eight studies and by measuring nicotine in blood in one study. As reported in three studies $[30,31,35]$, the mean duration between HIV diagnosis and inclusion in the original study varied from 10.5 to 15.2 years. The proportion of people on ART varied from 36 to $100 \%$ in six studies. The mean age of participants varied from 35 to 53 years. The proportion of male participants varied from 31 to $100 \%$. The mean/median CD4 cells count varied from 133 to 496 cells $/ \mathrm{mm}^{3}$ from five studies. The proportion of PLWH with detectable viral load at study initiation varied from 18 to $70 \%$ from three studies. The median duration of follow-up varied from 1.7 to 9.6 years from six studies. Counselling for tobacco smoking cessation was performed only in one study (Table S3).

\section{Smoking change patterns}

Meta-analysis results are presented in Table 1 . The prevalence of current smokers at study initiation (38.1, 95\% CI: 24.7-52.6) was in the range of the prevalence at the end of the study (35.6, 95\% CI: 6.6-72.5) (Fig. 1). In the same way, the prevalence of former smokers at study initiation (21.4, 95\% CI: 15.1-28.5) was in the range of the prevalence at the end of the study $(17.6,95 \% \mathrm{CI}$ : 5.1-35.5) (Fig. 1). The prevalence of never smokers decreased from study initiation (28.6, 95\% CI: 20.3-37.8) to study completion $(6.1,95 \% C I$ : $4.8-7.6)$, although only one study was included for study completion (Fig. 2). There was a low prevalence of people starting smoking during the study: shifting from never to current smoking (2.1, 95\% CI: 0.9-3.6) and from former to current smoking (1.5, 95\% CI: 0.6-2.9) (Fig. 2). The prevalence of shifting from current to former smoker was 10.5\% (95\% CI: 7.2-14.4) (Fig. 2). The prevalence for staying in the 
Table 1 Patterns of tobacco smoking change in people living with HIV

\begin{tabular}{|c|c|c|c|c|c|c|c|c|}
\hline & \multirow{2}{*}{$\begin{array}{l}\text { Prevalence } \\
(95 \% \text { Cl) }\end{array}$} & \multirow{2}{*}{$\begin{array}{l}95 \% \\
\text { Prediction } \\
\text { interval }\end{array}$} & \multirow{2}{*}{$\begin{array}{l}N \\
\text { studies }\end{array}$} & \multirow{2}{*}{$\begin{array}{l}N \\
\text { participants }\end{array}$} & \multicolumn{3}{|l|}{ Heterogeneity } & \multirow{2}{*}{$\begin{array}{l}P \text { Egger } \\
\text { test }\end{array}$} \\
\hline & & & & & $\mathrm{H}(954 \% \mathrm{Cl})$ & $P^{2}(95 \% C l)$ & $P$ value & \\
\hline Current smokers at study initiation & $38.1(24.7-52.6)$ & $1.5-87.4$ & 8 & 14446 & $15.7(14.2-17.3)$ & $99.6(99.5-99.7)$ & $<0.0001$ & 0.458 \\
\hline Current smokers at study completion & $35.6(6.6-72.5)$ & $0.0-100$ & 4 & 8312 & $24.2(21.7-27.0)$ & $99.8(99.8-99.9)$ & $<0.0001$ & 0.321 \\
\hline Former smokers at study initiation & $21.4(15.1-28.5)$ & $3.1-49.8$ & 8 & 25125 & $11.7(10.4-13.2)$ & $99.3(99.1-99.4)$ & $<0.0001$ & 0.528 \\
\hline Former smokers at study completion & $17.6(5.1-35.5)$ & NA & 2 & 1358 & 6.4 & $97.5(93.9-99.0)$ & $<0.0001$ & NA \\
\hline Never smokers at study initiation & $28.6(20.3-37.8)$ & $4.0-63.8$ & 8 & 25125 & $14.0(12.6-15.5)$ & $99.5(99.4-99.6)$ & $<0.0001$ & 0.930 \\
\hline Never smokers at study completion & $6.1(4.8-7.6)$ & NA & 1 & 1062 & NA & NA & NA & NA \\
\hline $\begin{array}{l}\text { Shifting from never to current smoking } \\
\text { during study }\end{array}$ & $2.1(0.9-3.6)$ & NA & 2 & 1518 & 1.7 & $65.9(0.0-92.3)$ & 0.087 & NA \\
\hline $\begin{array}{l}\text { Shifting from former to current smoking } \\
\text { during study }\end{array}$ & $1.5(0.6-2.9)$ & NA & 1 & 456 & NA & NA & NA & NA \\
\hline $\begin{array}{l}\text { Stopped smoking during the study } \\
\text { (shifting from current to former smoker) }\end{array}$ & $10.5(7.2-14.4)$ & $0.3-31.8$ & 4 & 2191 & $2.6(1.8-4.1)$ & $85.5(64.2-94.1)$ & 0.0001 & 0.520 \\
\hline Stayed in the "never smoking" category & $10.1(3.0-20.5)$ & NA & 2 & 1439 & 5.0 & $96.0(88.7-98.6)$ & $<0.0001$ & NA \\
\hline Tried to quit smoking but failed & $7.1(4.4-10.3)$ & NA & 1 & 296 & NA & NA & NA & NA \\
\hline $\begin{array}{l}\text { Willed to quit smoking but did not } \\
\text { initiate any quitting attempt }\end{array}$ & $0.4(0.0-1.3)$ & NA & 1 & 456 & NA & NA & NA & NA \\
\hline
\end{tabular}

HIV Human immunodeficiency virus; NA not applicable; Cl Confidence interval

never smoking category was $10.1 \%$ (95\% CI: 3.0-20.5) (Fig. 2). Substantial heterogeneity was found, however, there was no publication bias for all analyses (Table 1).

\section{Discussion}

This systematic review and meta-analysis aimed to investigate changes in smoking patterns among people living with HIV, globally. Although a high heterogeneity between studies was observed, the proportion of current and former smokers decreased slightly over time, around 2.5 and $3.8 \%$, respectively. However, the proportion of never smokers decreased sharply by $22.5 \%$, and there were 2.1 and $1.5 \%$ PLWH who shifted from never and former smoking to current smoking, respectively. On the other hand, $10.5 \%$ PLWH shifted from current to former smoking, $7.1 \%$ tried to quit tobacco consumption but failed, $10.1 \%$ stayed in the "never smoking" category over time and $0.4 \%$ willed to quit smoking but did not initiate any quitting attempt.

Clearly, the proportion of current and former smokers did not decrease significantly over time, despite the knowing harmful effects of tobacco smoking on PLWH's health [3, 4, 7-11]. What's worse, the proportion of never smokers decreased sharply over time, indicating perhaps that in the course of HIV-infection, a huge number of people started smoking. Actually, it has been argued that tobacco is being used among PLWH to cope with HIVrelated symptoms such as neuropathic pains, anxiety, stress, and depression, all of which have been shown highly prevalent in this population [37, 38]. In addition, Mdege et al. bolstered that PLWH tend to express an inaccurate perception of their life expectancy which consequently affects their perceived susceptibility to the risk of tobacco use [18]. These facts brought the previous authors to suggest that dissemination of information on harmful effects of tobacco consumption might not be enough to reduce its use among PLWH [18].

Although it was reported from one study, the present review showed that no more than $0.4 \%$ PLWH willed to quit tobacco smoking but did not initiate any attempt. In accordance with the trans-theoretical model of health behaviour change used to describe the psychological mindset of smokers [39], it can be inferred that most patients were still in the precontemplation phase while a minority of them might have reached the contemplation, preparation, action or even maintenance phase. Indeed, only $7.1 \%$ of PLWH tried to quit tobacco consumption but failed, corroborating other estimates driven from general smokers [40]. Kwong and Bouchard-Miller showed that quitting tobacco consumption is hard to reach and maintain because of both the addictive potential of nicotine and the withdrawal symptoms that accompany cessation [41]. Although there was no information about the reasons underlying these failures, one can easily suggest that these patients received no support and unsuccessfully tried to quit tobacco use by their own means [42, 43]. Accordingly, it has been demonstrated that smokers who had received adequate assistance and support towards smoking cessation had nearly doubled their success rate at 12 months in comparison to those who received no assistance [44].

This puts in light the paramount role that health care providers should play in helping PLWH to quit tobacco 
A. Current smokers at study initiation

\begin{tabular}{|c|c|c|c|c|c|c|}
\hline Author, Year & Cases & Sample & \multicolumn{2}{|c|}{ Prevalence (\%) } & Prevalence (\%) & $(95 \% \mathrm{Cl})$ \\
\hline Kruse, 2014 & 46 & 456 & & & 10.1 & {$[7.5 ; 13.2]$} \\
\hline Akhtar-Khaleel, 2016 & 1457 & 6577 & + & & 22.2 & {$[21.2 ; 23.2]$} \\
\hline Gamarel, 2016 & 106 & 377 & + & & 28.1 & {$[23.6 ; 32.9]$} \\
\hline Shirley, 2013 & 58 & 200 & 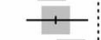 & & 29.0 & {$[22.8 ; 35.8]$} \\
\hline Kelly, 2016 & 324 & 1005 & + & & 32.2 & {$[29.4 ; 35.2]$} \\
\hline Bekele, 2017 & 1760 & 4473 & & & 39.3 & {$[37.9 ; 40.8]$} \\
\hline Vijayaraghavan, 2014 & 218 & 296 & & 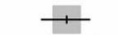 & 73.6 & {$[68.2 ; 78.6]$} \\
\hline Costiniuk, 2016 & 817 & 1062 & & + & 76.9 & {$[74.3 ; 79.4]$} \\
\hline Overall Prevalence & & 14446 & & & 38.1 & {$[24.7 ; 52.6]$} \\
\hline Prediction interval & & & & & & {$[1.5 ; 87.4]$} \\
\hline Heterogeneity: $I^{2}=99.6^{\circ}$ & $\%[99.5 \%$; & ; 99.7\%], $P$ & 20 & 80 & & \\
\hline
\end{tabular}

\section{B. Current smokers at study completion}

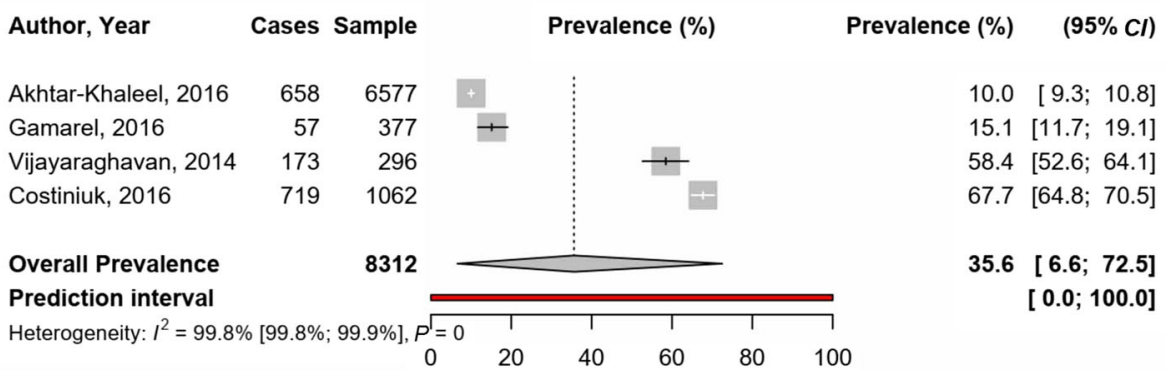

\section{Former smokers at study initiation}

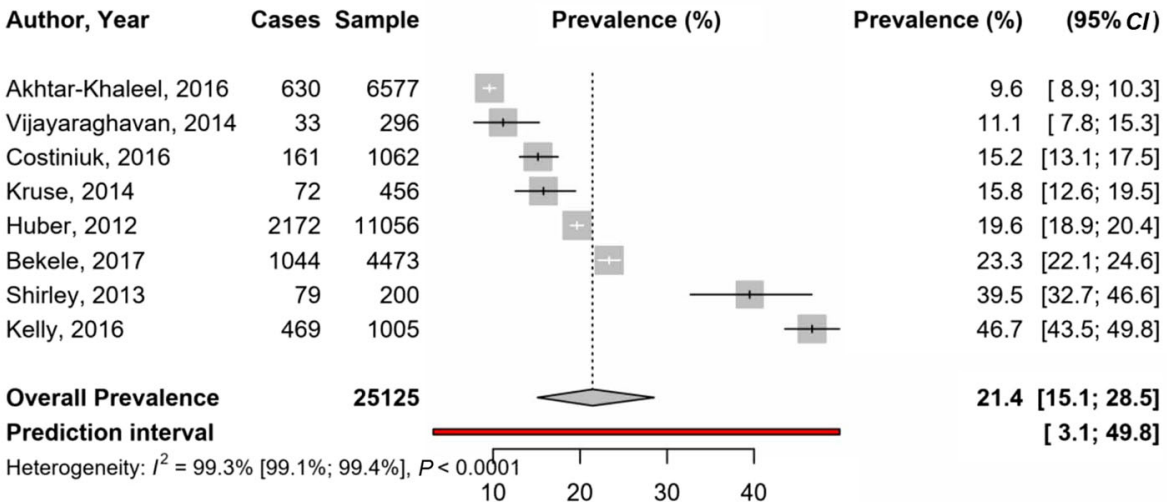

\section{Former smokers at study completion}

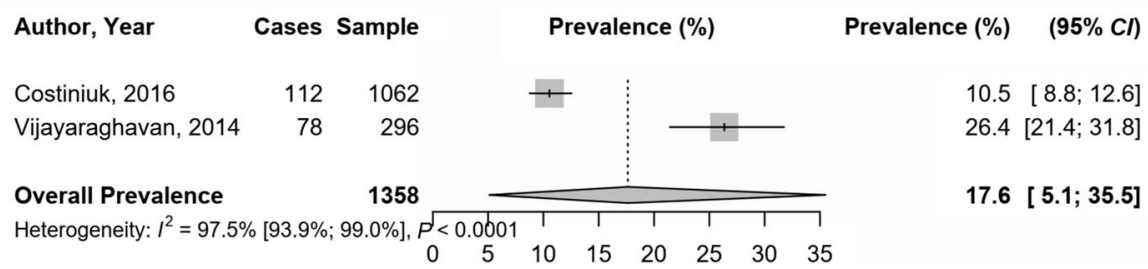

Fig. 1 Meta-analysis prevalence of current and former smokers at study initiation and completion in the global population living with HIV. HIV: Human immunodeficiency virus

use, which commands that these care givers receive appropriate knowledge and competencies to deliver the right support. A recent review showed for instance that the success of a smoking-cessation intervention is also tributary of care providers' knowledge and confidence to deliver the intervention [16]. Many types of healthcare 
A. Never smokers at study initiation

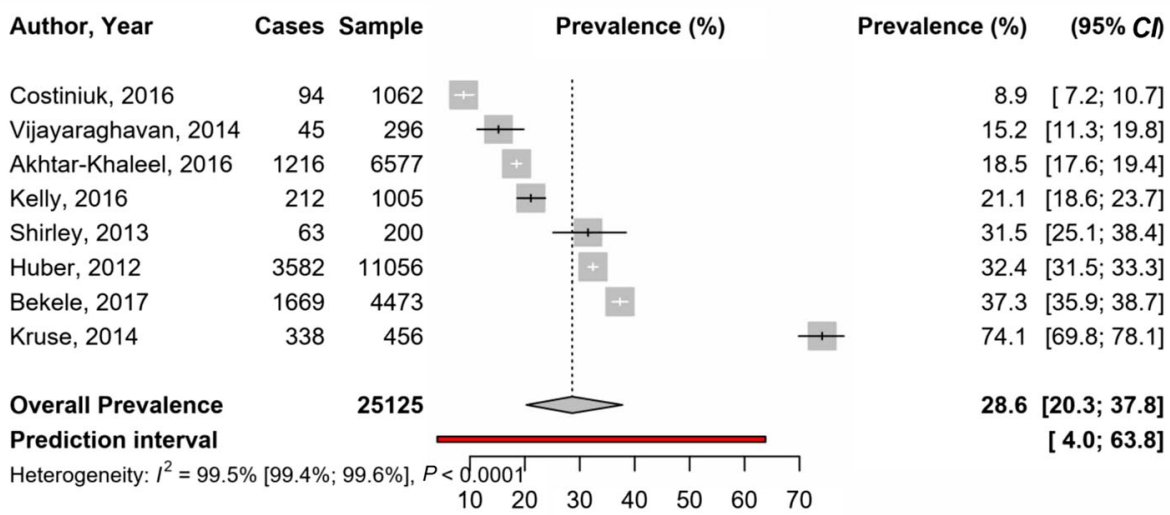

B. Shifting from never to current smoking during study

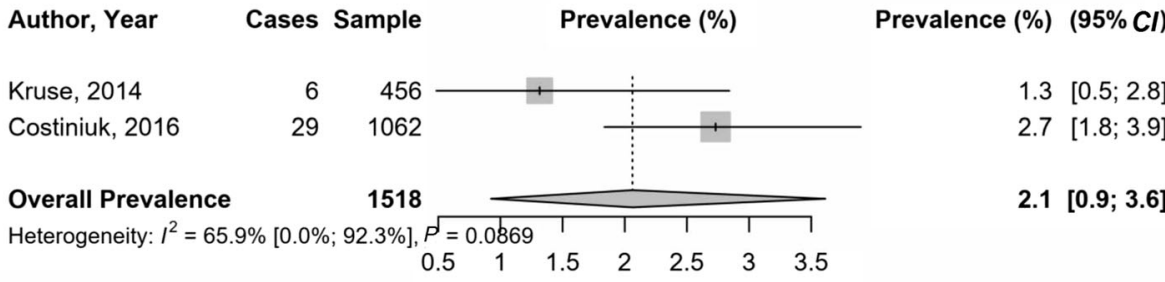

\section{Shifting from current to former smoker}
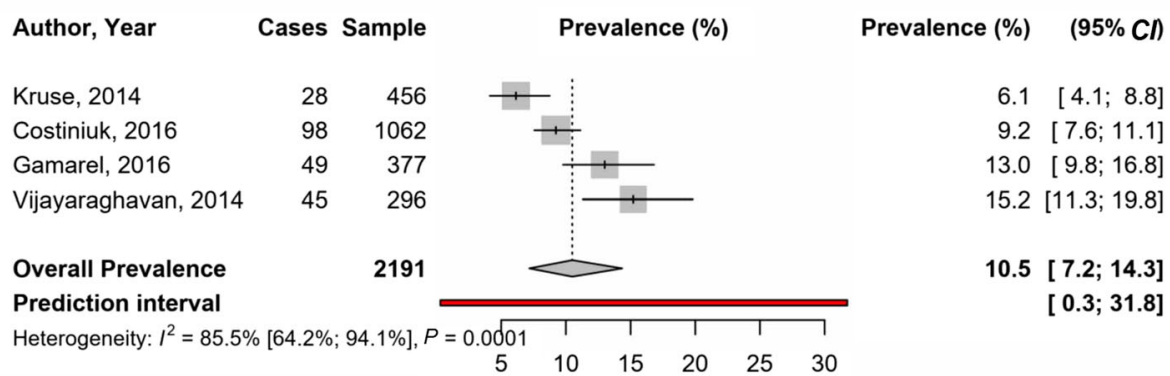

D. Stayed in the "never smoking" category

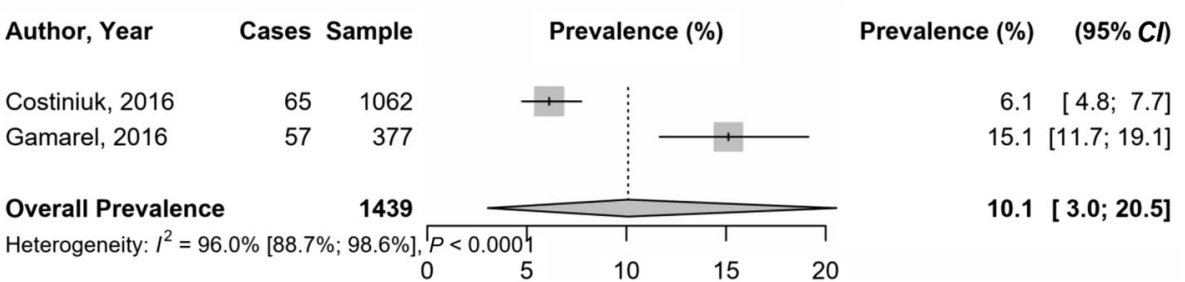

Fig. 2 Meta-analysis prevalence of never and shifting smokers in the global population living with HIV. HIV: Human immunodeficiency virus

providers are able to provide support towards smoking cessation including nurses, physicians, community and social workers, and health educators, all of whom are part of the HIV care givers' team. It was shown that using multiple providers in a team approach (such as a physician and a nurse) could further enhance quit rates [41]. Therefore, tobacco use services ought to be integrated within HIV programs and be given full priority [18]. However, and considering the overwhelming task of managing HIV infection and its complications, smoking cessation may represent less of a priority from both providers' and patients' perspectives. Additionally, the heavy workload and shortages of health personnel which are particularly characteristic of low-income countries make time to be provided for extensive counselling very limited $[45,46]$. These challenges need to be taken into consideration for the success of smoking cessation interventions in PLWH, especially in developing countries and sub-Sahara African countries. Indeed, 70\% of PLWH reside in sub-Sahara Africa [6], a region with weak healthcare systems. Integration 
of tobacco use services in HIV programs and strengthening skills of HIV healthcare workers on strategies to help quitting tobacco consumption should be prioritized in this region as well as resources to be allocated for the task.

On the other hand and concerning what specific interventions should be implemented for PLWH who smoke, a review of tested interventions came to the conclusion that interventions may be more effective when its components are tailored to the unique needs of the target population [14]. For instance, depression and co-dependency on other substances such as alcohol and illicit drugs should be adequately addressed as part of a smoking cessation program for PLWH [16, 41]. In accordance with international guidelines, all trials implemented multifaceted interventions and utilized a combination of motivational interviewing/counselling techniques and pharmacotherapy (either nicotine-replacement therapy, nicotine agonists, or antidepressant therapy, unless pharmacotherapy is contraindicated) with varying degrees of intensity [16]. Other non-pharmacologic methods tested included telephone counselling, online quit programs, and cell phone counselling programs $[16,41]$. Notwithstanding, it was emphasized the need for interventions that utilize multiple strategies and deliver highly intense interventions at multiple sessions [16, 41]. Moreover, effective interventions have to follow the " $5 \mathrm{~A}$ 's" of smoking-cessation counselling, notably: ask about tobacco use, advise to quit, assess willingness to make a quit attempt, assist in quitting attempt, and arrange follow-up [16, 41].

Along with these specific interventions and in compliance with tobacco control policies derived from the WHO Framework Convention on Tobacco Control [47], some population-based interventions have yielded satisfactory outcomes towards reducing cigarette smoking and smoking-related disease and death, especially among subpopulations with the highest smoking prevalence. These strategies include tobacco price increases, comprehensive smoke-free laws, anti-tobacco mass media campaigns, and barrier-free access to tobacco cessation counselling and medications [48]. Definitely, there is crucial need for further research to better explore effective and cost-effective tobacco cessation interventions for PLWH that would be appropriate and scalable worldwide, especially in resource-constrained countries [18].

The present study should be interpreted in the context of some limitations. First, a substantial heterogeneity between studies included in the meta-analysis was observed, which is quite common to most systematic review of this kind and somewhat inevitable as well [49]. However, due to low number of studies, it was not possible to perform subgroup and meta-regression analyses to investigate sources of heterogeneity that may have influenced smoking pattern changes. These sources of heterogeneity might have included geographic, legal, cultural, clinical, socioeconomic, and demographic characteristics in different studies. Second, studies were disproportionally represented across various regions of the world, were not all population-based and nationally representative of PLWH; these facts may impede the translatability of these results to the entire globe. In addition, most studies were from high-income countries and only one study was from Africa, the epicentre of HIV infection with more than $70 \%$ of PLWH. It is therefore important to take this into account since findings of this study could more reflect the face of the public health concern in high income countries. This calls for more research in the context where it is most needed. Third, history of smoking was self-reported in these studies and some parameters were present in only one study, which may have introduced underestimation or overestimation of smoking status and changes. Nevertheless, and to the very best of the authors' knowledge, this is the first systematic review and meta-analysis which has investigated changes in smoking behaviours among PLWH. A rigorous methodology was developed and robust statistical procedures were applied to examine the review's research questions.

\section{Conclusions}

This systematic review and meta-analysis revealed no positive changes in smoking patterns among people living with HIV, globally. These results put in light the crucial need to settle the fight against tobacco consumption as a priority in HIV care delivery in order to prevent the excess morbidity and mortality secondary to tobacco-related diseases in PLWH. Accordingly, cost-effective and appropriate interventions should be identified, that should be tailored to individual needs. Tobacco cessation services should be integrated in HIV programs and smoke-free policies should be implemented in HIV-treatment facilities. Having a pivotal role to play, HIV healthcare providers' awareness and skills should be reinforced and upgraded to provide adequate cessation advice to patients and awareness of the harmful effects of smoking consumption and subsequent benefits of quitting particularly for PLWH should be increased. Beyond and considering the low number of studies included in this review, there is need to carry-out further well-designed researches to better investigate changes in smoking patterns in the course of HIV-infection.

\section{Supplementary information}

Supplementary information accompanies this paper at https://doi.org/10. 1186/s40249-020-00644-z.

Additional file 1: Table S1. MOOSE checklist Table S2. Search strategy in PubMed Table S3. Characteristics of included studies Figure S1. Process of identification and selection of studies for inclusion in the review (PRISMA flow diagram) 


\section{Abbreviations}

ART: Antiretroviral therapy; HIV: Human immunodeficiency virus; PLWH: People living with HIV; WHO: World Health Organisation

\section{Acknowledgments}

None to disclose.

\section{Ethical approval and consent to participate}

Not applicable.

\section{Data sharing statement}

All data generated or analysed during this study are included in this published article and its supplementary information files.

\section{Authors' contributions}

Conception and design: JRN and JJB. Search strategy: JJB. Study selection: JRN, DNT, JJB. Data extraction: JRN, DNT, JJB. Data synthesis and analysis: JJB and JRN. Data interpretation: JRN, JJN, JJB. Manuscript drafting: JRN, DNT, and JJB. Manuscript revision: JRN, DNT, JJN, JJB. Guarantor of the review: JRN. Approved the final version of the manuscript: All authors.

\section{Funding}

The authors did not receive any funding, be it from a public, private or notfor-profit institution.

\section{Availability of data and materials}

Not applicable.

\section{Consent for publication}

Not applicable.

\section{Competing interests}

The authors declare that they have no competing interests.

\section{Author details}

'Department of Public Health, Faculty of Medicine and Biomedical Sciences of the University of Yaoundé I, Yaoundé, Cameroon. ${ }^{2}$ Department for the Control of Disease, Epidemics and Pandemics, Ministry of Public Health, Yaoundé, Cameroon. ${ }^{3}$ Centre for Heart Rhythm Disorders, University of Adelaide and Royal Adelaide Hospital, Adelaide, Australia. ${ }^{4}$ Department of Epidemiology and Public Health, Centre Pasteur of Cameroon, PO Box 1274 Yaoundé, Cameroon. ${ }^{5}$ School of Public Health, Faculty of Medicine, University of Paris Sud XI, Le Kremlin Bicêtre, France.

\section{Received: 7 June 2019 Accepted: 3 March 2020}

\section{Published online: 16 April 2020}

\section{References}

1. World Health Organization. WHO report on the global tobacco epidemic 2017. 2017. http://www.who.int/tobacco/global_report/2017/en/. Accessed 3 Mar 2019.

2. Mercié P, Arsandaux J, Katlama C, Ferret S, Beuscart A, Spadone C, Duvivier C, Reynes J, Wirth N, Moinot L, et al. Efficacy and safety of varenicline for smoking cessation in people living with HIV in France (ANRS 144 interACTIV): a randomised controlled phase 3 clinical trial. Lancet HIV. 2018;5: e126-35..

3. Calvo M, Laguno M, Martinez M, Martinez E. Effects of tobacco smoking on HIV-infected individuals. AIDS Rev. 2015:17:47-55.

4. Shirley DK, Kaner RJ, Glesby MJ. Effects of smoking on non-AIDS-related morbidity in HIV-infected patients. Clin Infect Dis. 2013;57:275-82.

5. Bigna JJ, Kenne AM, Asangbeh SL, Sibetcheu AT. Prevalence of chronic obstructive pulmonary disease in the global population with HIV: a systematic review and meta-analysis. Lancet Glob Health. 2018;6:e193202.

6. UNAIDS. Global HIV \& AIDS statistics - 2019 fact sheet. 2019. https://www. unaids.org/en/resources/fact-sheet. Accessed 5 Jul 2019.

7. Cropsey KL, Willig JH, Mugavero MJ, Crane HM, McCullumsmith C, Lawrence S, Raper JL, Mathews WC, Boswell S, Kitahata MM, et al. Cigarette smokers are less likely to have undetectable viral loads: results from four HIV clinics. Addict Med. 2016;10:13-9.
8. Marshall MM, McCormack MC, Kirk GD. Effect of cigarette smoking on HIV acquisition, progression, and mortality. AIDS Educ Prev. 2009;21:28-39.

9. Nguyen NT, Tran BX, Hwang LY, Markham CM, Swartz MD, Vidrine Jl, Phan $H T$, Latkin CA, Vidrine DJ. Effects of cigarette smoking and nicotine dependence on adherence to antiretroviral therapy among HIV-positive patients in Vietnam. AIDS Care. 2016:28:359-64.

10. O'Cleirigh C, Valentine SE, Pinkston M, Herman D, Bedoya CA, Gordon JR, Safren SA. The unique challenges facing HIV-positive patients who smoke cigarettes: HIV viremia, ART adherence, engagement in HIV care, and concurrent substance use. AIDS Behav. 2015;19:178-85.

11. Lifson AR, Lando HA. Smoking and HIV: prevalence, health risks, and cessation strategies. Curr HIV/AIDS Rep. 2012;9:223-30.

12. Batista J, Militao de Albuquerque Mde F, Ximenes RA, Miranda-Filho Dde B, Lacerda de Melo HR, Maruza M, Moura LV, Pinto da Costa Ferraz EJ, Rodrigues LC. Prevalence and socioeconomic factors associated with smoking in people living with HIV by sex, in Recife, Brazil. Rev Bras Epidemiol. 2013:16:432-43.

13. Park LS, Hernandez-Ramirez RU, Silverberg MJ, Crothers K, Dubrow R. Prevalence of non-HIV cancer risk factors in persons living with HIV/AIDS: a meta-analysis. Aids. 2016;30:273-91.

14. Weinberger AH, Smith PH, Funk AP, Rabin S, Shuter J. Sex Differences in Tobacco Use Among Persons Living With HIV/AIDS: A Systematic Review and Meta-Analysis. J Acquir Immune Defic Syndr. 2017;74:439-53.

15. Nguyen NP, Tran BX, Hwang LY, Markham CM, Swartz MD, Phan HT, Nong VM, Nguyen CT, Nguyen AH, Latkin CA, et al. Prevalence of cigarette smoking and associated factors in a large sample of HIV-positive patients receiving antiretroviral therapy in Vietnam. PLoS One. 2015;10:e0118185.

16. Moscou-Jackson G, Commodore-Mensah Y, Farley J, DiGiacomo M. Smoking-cessation interventions in people living with HIV infection: a systematic review. J Assoc Nurses AIDS Care. 2014;25:32-45.

17. Mdodo R, Frazier EL, Dube SR, Mattson CL, Sutton MY, Brooks JT, Skarbinski J. Cigarette smoking prevalence among adults with HIV compared with the general adult population in the United States: cross-sectional surveys. Ann Intern Med. 2015:162:335-44.

18. Mdege ND, Shah S, Ayo-Yusuf OA, Hakim J, Siddiqi K. Tobacco use among people living with HIV: analysis of data from demographic and health surveys from 28 low-income and middle-income countries. Lancet Glob Health. 2017:5:e578-92.

19. Bekele T, Rueda S, Gardner S, Raboud J, Smieja M, Kennedy R, Fletcher D, Burchell AN, Bacon J, Rourke SB. Trends and correlates of cigarette smoking and its impacts on health-related quality of life among people living with HIV: findings from the Ontario HIV Treatment Network cohort study, 20082014. AIDS Patient Care STDs. 2017:31:49-59.

20. Krause DD, May WL, Butler KR Jr. Determining unmet, adequately met, and overly met needs for health care and services for persons living with HIV/ AIDS in Mississippi. AIDS Care. 2013;25:973-9.

21. Ng YC, Caires A. The health promotion model in HIV care. Aquichan. 2016; 16:418-29.

22. Centers for Reviews and Dissemination. CRD's quidance for undertaking reviews in healthcare. 2009. http://www.york.ac.uk/crd/SysRev/!SSL!/ WebHelp/SysRev3.htm. Accessed 3 Mar 2019.

23. Viera AJ, Garrett JM. Understanding interobserver agreement: the kappa statistic. Fam Med. 2005;37:360-3.

24. Wells GA, Shea B, O'Connell D, Peterson J, Welch V, Losos M, Tugwell P. The Newcastle-Ottawa scale (NOS) for assessing the quality of nonrandomised studies in meta-analyses. 2019. http://www.ohri.ca/programs/clinical_ epidemiology/oxford.asp. Accessed 3 Mar 2019.

25. Barendregt JJ, Doi SA, Lee YY, Norman RE, Vos T. Meta-analysis of prevalence. J Epidemiol Community Health. 2013;67:974-8.

26. Cochran GW. The combination of estimates from different experiments. Biometrics. 1954;10:101-29.

27. Higgins JP, Thompson SG. Quantifying heterogeneity in a meta-analysis Stat Med. 2002;21:1539-58

28. Egger M, Davey Smith G, Schneider M, Minder C. Bias in meta-analysis detected by a simple, graphical test. BMJ. 1997;315:629-34

29. Akhtar-Khaleel WZ, Cook RL, Shoptaw S, Surkan PJ, Teplin LA, Stall R, Beyth RJ, Manini TM, Plankey M. Long-term cigarette smoking trajectories among HIV-seropositive and Seronegative MSM in the multicenter AIDS cohort study. AIDS Behav. 2016;20:1713-21.

30. Costiniuk CT, Brunet L, Rollet-Kurhajec KC, Cooper CL, Walmsley SL, Gill MJ, Martel-Laferriere $V$, Klein MB. Tobacco smoking is not associated with 
accelerated liver disease in human immunodeficiency virus-hepatitis $C$ coinfection: a longitudinal cohort analysis. Open Forum Infect Dis. 2016;3(2): ofw050.

31. Gamarel KE, Mereish EH, Manning D, Iwamoto M, Operario D, Nemoto T. Minority stress, smoking patterns, and cessation attempts: findings from a community-sample of transgender women in the San Francisco Bay Area. Nicotine Tob Res. 2016;18:306-13.

32. Huber M, Ledergerber B, Sauter R, Young J, Fehr J, Cusini A, Battegay M, Calmy A, Orasch C, Nicca D, et al. Outcome of smoking cessation counselling of HIV-positive persons by HIV care physicians. HIV Med. 2012; 13:387-97.

33. Kelly SG, Plankey M, Post WS, Li X, Stall R, Jacobson LP, Witt MD, Kingsley L, Cox C, Budoff M, et al. Associations between tobacco, alcohol, and drug use with coronary artery plaque among HIV-infected and uninfected men in the multicenter AIDS cohort study. PLoS One. 2016:11(1):e0147822.

34. Kruse GR, Bangsberg DR, Hahn JA, Haberer JE, Hunt PW, Muzoora C, Bennett JP, Martin JN, Rigotti NA. Tobacco use among adults initiating treatment for HIV infection in rural Uganda. AIDS Behav. 2014;18:1381-9.

35. Shirley DK, Kesari RK, Glesby MJ. Factors associated with smoking in HIVinfected patients and potential barriers to cessation. AIDS Patient Care STDs. 2013;27:604-12.

36. Vijayaraghavan M, Penko J, Vittinghoff E, Bangsberg DR, Miaskowski C, Kushel MB. Smoking behaviors in a community-based cohort of HIVinfected indigent adults. AIDS Behav. 2014;18:535-43.

37. Bigna JJ, Tounouga DN, Kenne AM, Djikeussi TK, Foka AJ, Um LN, Asangbeh SL, Sibetcheu AT, Kaze AD, Ndangang MS, et al. Epidemiology of depressive disorders in people living with HIV in Africa: a systematic review and metaanalysis: burden of depression in HIV in Africa. Gen Hosp Psychiatry. 2018; 57:13-22.

38. Humfleet GL, Delucchi K, Kelley K, Hall SM, Dilley J, Harrison G. Characteristics of HIV-positive cigarette smokers: a sample of smokers facing multiple challenges. AIDS Educ Prev. 2009;21:54-64.

39. Prochaska JO, Velicer WF. The transtheoretical model of health behavior change. Am J Health Promot. 1997;12:38-48.

40. Hughes JR, Keely J, Naud S. Shape of the relapse curve and long-term abstinence among untreated smokers. Addiction. 2004;99:29-38.

41. Kwong J, Bouchard-Miller K. Smoking cessation for persons living with HIV a review of currently available interventions. J Assoc Nurses AIDS Care. 2010; 21:3-10.

42. Chaiton M, Diemert L, Cohen JE, Bondy SJ, Selby P, Philipneri A, Schwartz R. Estimating the number of quit attempts it takes to quit smoking successfully in a longitudinal cohort of smokers. BMJ Open. 2016;6:e011045.

43. Borland R, Partos TR, Yong H-H, Cummings KM, Hyland A. How much unsuccessful quitting activity is going on among adult smokers? Data from the International Tobacco Control Four Country cohort survey. Addiction. 2012;107:673-82

44. West R, Hajek P, Stead L, Stapleton J. Outcome criteria in smoking cessation trials: proposal for a common standard. Addiction. 2005;100:299-303.

45. Tuthill EL, Chan J, Butler LM. Challenges faced by health-care providers offering infant-feeding counseling to HIV-positive women in sub-Saharan Africa: a review of current research. AIDS Care. 2015;27:17-24.

46. Evans C, Nalubega S, McLuskey J, Darlington N, Croston M, Bath-Hextall F. The views and experiences of nurses and midwives in the provision and management of provider-initiated HIV testing and counseling: a systematic review of qualitative evidence. JBI Database System Rev Implement Rep. 2016;13:130-286.

47. World Health Organization. WHO Framework Convention on Tobacco Control. 2003. https://www.who.int/fctc/text_download/en/. Accessed 3 Mar 2019.

48. Jamal A, King BA, Neff $L$, Whitmill J, Babb SD, Graffunder CM. Current cigarette smoking among adults - United States, 2005-2015. MMWR Morb Mortal Wkly Rep. 2016;65:1205-11.

49. Bigna JJ, Nansseu JR, Kaze AD, Noubiap JJ. The Authors Respond. Epidemiology. 2018;29:e58-9.

\section{Ready to submit your research? Choose BMC and benefit from:}

- fast, convenient online submission

- thorough peer review by experienced researchers in your field

- rapid publication on acceptance

- support for research data, including large and complex data types

- gold Open Access which fosters wider collaboration and increased citations

- maximum visibility for your research: over $100 \mathrm{M}$ website views per year

At BMC, research is always in progress.

Learn more biomedcentral.com/submissions 